\title{
Rapid turnover of the recirculating lymphocyte pool in vivo
}

\author{
Alan J. Young ${ }^{1-3}$ and John B. Hay 1,2,4 \\ ${ }^{1}$ Trauma Research Program, Sunnybrook Health Science Centre, New York, Ontario, Canada \\ Departments of ${ }^{2}$ Immunology and ${ }^{4}$ Pathology, University of Toronto, Toronto, Canada \\ ${ }^{3}$ Present address: Basel Institute for Immunology, Grenzacherstrasse 487, Postfach, $\mathrm{CH}-4005$ Basel, \\ Switzerland
}

Keywords: lymphocytes, cell movement, sheep, cell tracking, lymphatic system, cell lifespan

\begin{abstract}
Lymphocytes are unique among blood cells in their capacity to continually recirculate between blood and the tissues via the lymph. Prevlous estimates of lymphocyte llfespan In vivo and the turnover of the recirculating lymphocyte pool have been deduced from Indirect labeling techniques. Using the fluorescent dye PKH-26, individual labeled cells have been tracked in sheep for perlods $>2$ months. By direct measurement their Ilfespan was calculated. Thls label was found to be stable in vivo, allowing long-term analysis of the characteristics of the recirculating lymphocyte pool. It is possible to calculate the rate of turnover of cells of the recirculating pool based on the rate at which labeled cells dlsappear from the lymphatic clrculation. The recirculating lymphocyte pool was found to repopulate itself every $16.5 \pm 3.0$ days. Using thls label, It was estimated that recirculating lymphocytes divide on average once every $29.8 \pm 6.8$ days. Labeled erythrocytes were also examined and found to have an average lifespan of 153 days, demonstrating no dye los8 over the 2 month perlod of observation. These date suggest that the recirculating lymphocyte pool is a highly dynamic compartment, with a high rate of turnover and peripheral cell division in vivo. This is the first report of the direct measurement of the In vivo turnover of recirculating lymphocyte pools, and this method may now be used to further analyze the Iffespan of individual lymphocyte subsets and the In vivo lifespen of other cell types in vivo.
\end{abstract}

\section{Introduction}

One of the basic hallmarks of the immune system is the characteristic of Immunological memory. It was accepted for many years that this phenomenon is due to a long-lived population of lymphocytes specific for previously encountered antigen. However, in recent years, the mechanism for the long-term maintenance of immunological memory in vivo has come into question, along with the lifespan of lymphocytes (1). In vivo transfer experiments have suggested that, in mice, memory may be due to a short-lived population of lymphocytes $(2,3)$. The physiological process of lymphocyte migration has been demonstrated to be absolutely required for the immunological mechanisms of surveillance and memory (4). Animals deprived of lymphocytes recirculating through antigen-stimulated lymph nodes have been shown to lose characteristic systemic memory responses in vivo, although local secondary responses can still be detected (4). The systemic component of memory therefore may lie within the recirculating pool of lymphocytes.
In an effort to understand the nature of lymphocyte recirculation, a great deal of information has been obtained regarding the molecular mechanisms of lymphocyte-endothelial transmigration (5). Much of this data has been obtained in rodent models. In addition, rodent models have been used extensively in the study of lymphocyte homing (6). However, only in a large animal model is it possible to study the recirculation of lymphocytes through tissues by direct cannulation of individual lymphatic vessels (7). As a result, more is known regarding the physiology of lymphocyte traffic in sheep than in any other species $(8-10)$. Lymphatic cannulation provides direct access to a virtually pure population of recirculating lymphocytes, with minimum in vitro manipulation. However, previous studies have been hampered by the use of lymphocyte tracking labels which permit only short-term experiments, generally lasting a few days. No long-term tracking of labeled cells has been possible. In addition, previous estimates of cell lifespans in vivo have also involved the use of indirect 
techniques, such as the persistence of altered karyotypes, in vivo incorporation of labeled nucleotides or arrest of cell proliferation (11-13). Some of these studies were hampered by unequal precursor distribution during labeling as well as cellular toxicity $(14,15)$. Furthermore, these methods do not permit precise mathematical calculation of in vivo cell turnover based upon direct measurement.

Several different labeling techniques have been used to establish the lifespan of erythrocytes in vivo. The majority of red blood cell data has been obtained through the use of radiolabeled compounds. Using $\left[{ }^{32} \mathrm{P}\right]$ diisopropyl fluorophosphate, ${ }^{51} \mathrm{Cr}$ or ${ }^{53} \mathrm{Fe}$, a variety of values of red blood cell lifespans has been obtained $(16,17)$. There are a number of difficulties in the use of these labeling techniques, including rapid elution rates $\left({ }^{51} \mathrm{Cr}\right)$, lengthy in vitro labelıng procedures ([32P]disopropyl fluorophosphate) and re-utilization of label in vivo $\left({ }^{53} \mathrm{Fe}\right)(12-14)$.

The development of the PKH family of lipophilic labels has allowed more direct measurement of cell lifespan to be undertaken (19). This label consists of a linker molecule which directly intercalates into lipophilic membranes. Fluorochromes can be attached to this linker, allowing a variety of new labels to be used. The green label PKH-2 has been found to be stable in vivo for long-term labeling studies (20). The red linker PKH-26 has previously been used to determine the lifespan of rabbit red blood cells in vivo (21). With respect to lymphocytes, in vitro data demonstrates the PKH label to be equally segregated to two daughter cells during cell division, suggestıng that direct measurement of rates of cell division in vivo may be based on halving of the fluorescence intensity of labeled cells following re-injection (19). Finally, the PKH-2 form of this label allows long-term tracking of the migratory behaviour of recirculating lymphocytes over periods of up to 3 months, with no apparent alteration in homing characteristics (20).

Based on the drainage rate of thoracic duct lymphocytes, the recirculating pool is thought to represent $\sim 10 \%$ of the total number of lymphocytes found in sheep or $\sim 1 \times 10^{11}$ lymphocytes in a $30 \mathrm{~kg}$ anımal (22). However, only $\sim 1 \times 10^{10}$ lymphocytes are found in the blood at any given time, indicating that $90 \%$ of the recirculating pool is located in a state of transit within lymphatics or secondary lymphoid tissue (22). The turnover of this pool and of its individual subset components is of direct relevance to a better understanding of the process of immunological memory. Using the PKH labels, it is possible to perform long-term analysis of the turnover of cells in the recirculating lymphocyte pool based on the rate at which labeled cells disappear from the blood and lymph. In addition, it is possible to calculate directly the rate of cell division in vivo based on the rate at which label is lost from injected cells The studies reported here involved labeling recirculating lymphocytes collected from efferent S.C. lymph with $\mathrm{PKH}-26$. Following re-injection, these cells were followed for periods of up to 3 months in vivo, for the first time directly measuring the turnover of the recirculating lymphocyte pool in vivo. Using this dye, it was possible to directly calculate the turnover rate of the recırculatıng pool in various tissues, including efferent s.c. lymph, efferent intestinal lymph and peripheral blood.

\section{Methods}

\section{Surgical procedures}

Randomly bred ewes of 8-10 months of age (30-35 kg) were acquired from the Le-Do sheep farm (Ajax, Ontario, Canada) All animals were induced with i.v. sodium pentothal and anesthesia maintained throughout surgery with inhaled halothane. Catheters were placed in the efferent lymphatics draining the prescapular, prefemoral and intestinal lymph nodes as previously described (23-25). Venous access was maintained by inserting a catheter attached to a three-way stopcock into the jugular vein. Following surgery, animals were allowed to recover for at least $24 \mathrm{~h}$ prior to any cell collections. In most experiments, catheters were tied-off to prevent excessive lymphocyte drainage from high-flow lymphatics following cell collection and labelıng, and surgeries undertaken 3-5 days later to establish catheters in smaller lymphatics for sampling. Typically, lymph would be collected from these smaller lymphatics for periods of 7-10 days, at which time catheters would be tied-off for an additional 7-10 days. New catheters would then be established for further sampling. Lymph collection proceeded until labeled cells became undetectable. The flow of lymph and the cell output from cannulated lymphatics was monitored throughout the experiment to monitor for excessive drainage of recirculatıng lymphocytes. All animals were housed in metabolism cages during lymph collection, and allowed free access to food and water throughout the experiment. All protocols conformed to the standards set by the Sunnybrook Health Science Centre Anımal Care Committee and the Canadian Council on Animal Care

\section{Cell collections}

Lymph was collected in sterile bottles attached to bottle holders sutured directly to the skın of the animal and contained 100 units heparin (Hepalean) and 20,000 iv units penicillin. Blood lymphocytes were prepared by collection of heparinized whole blood, followed by lysis in a solution containing $17 \mathrm{mM}$ Tris and $0.75 \%$ ammonium chloride. For analysis, cells were washed once in HBSS prior to fixation in a solution of $1 \%$ paraformaldehyde in PBS and storage at $4^{\circ} \mathrm{C}$

\section{Cell labeling}

Lymphocytes. Cells collected from efferent prescapular lymph were counted on a Coulter ZM Cell counter (Coulter Electronics, Hialeah, FL). For all experiments, overnight collections were used, representing $2-7 \times 10^{9}$ lymphocytes. Whole lymph cell pellets were washed three times in HBSS containıng $10 \%$ lymph plasma (HBSS/10\% plasma). Cells were then resuspended at a concentration of $1 \times 10^{8} \mathrm{cells} / \mathrm{ml}$ in the provided Diluent $C$ (Zynaxis Cell Science, Malvern, PA). PKH26 was diluted to a concentration of $8 \mu \mathrm{M}$ in an equal volume of Diluent $C$. The two mixtures were then combined and allowed to label for $2.5 \mathrm{~min}$. A 2-fold excess of HBSS/ $10 \%$ plasma was then added and the cells recovered by centrifugation. The cells were washed once in HBSS/10\% plasma and resuspended in $20 \mathrm{ml}$ autologous lymph plasma prior to re-injection. All cells were injected i.v. via the indwellıng 
venous catheter. Samples of unstaıned and stained cells were kept and fixed in paraformaldehyde for later analysis.

Erythrocytes. Whole blood $(20 \mathrm{ml})$ was collected and the cells were washed three times in HBSS/10\% plasma The cells were then resuspended in $20 \mathrm{ml}$ Diluent $\mathrm{C}$. Dye was added to a final concentration of $8 \mu \mathrm{M}$ to another $20 \mathrm{ml}$ of Diluent $\mathrm{C}$ and the two mixtures added together. The cells were allowed to label for $2.5 \mathrm{~min}$ and then diluted with a 2-fold excess of HBSS/10\% plasma. Following a wash as above, the cells were resuspended in autologous lymph plasma and reinjected i.v. Samples of stained and unstained cells were kept for analysis.

\section{Analysis}

All samples were fixed in $1 \%$ paraformaldehyde in PBS and stored at $4^{\circ} \mathrm{C}$ All samples from a single experiment were analyzed on a Coulter Elite flow cytometer at a single sittıng $\mathrm{PKH}-26$ was excited using a $488 \mathrm{~nm}$ argon laser and detected usıng a $575 \mathrm{~nm}$ band-pass filter At least $10^{5}$ lymphocytes were analyzed per sample, gated appropriately on forward and side scatter to include only small lymphocytes or red blood cells respectively. This allowed a calculation of the mean fluorescence intensity of $\mathrm{PKH}-26$ labeled cells, as well as calculation of the concentration of labeled cells in each collection.

\section{Statistics}

Lymphocytes. Samples included in analysis were taken at least $150 \mathrm{~h}$ after injection in order to minımıze varıability during equilibratıon of labeled cells. Mean fluorescence intensity and proportion of labeled cells was converted to the $\log _{10}$ These log data were then subjected to a least-squares regression against time to obtain the equation for the rate of disappearance. Least-squares regression was also performed on the linear data (26). The significance of the trend was assessed using a standard two-tailed $t$-test with a rejection value of $P>$ 0.05 . The half-life of the equation was then calculated from the slope of the line in the form $y=b x+a$ to obtain the rate of disappearance of labeled cells, termed the pool turnover rate, or the rate of loss of intensity of the labeled cells, termed the cell lifespan or division rate.

Erythrocytes. Samples included in analysis were taken at least $150 \mathrm{~h}$ after injection in order to minimize variability from equilibration of labeled cells Mean fluorescence intensity was converted to the $\log _{10}$ as above and subjected to a leastsquares regression. The proportion of labeled cells was directly subjected to a least-squares regression as well as a logarıthmıc least-squares regression as above (26). Statistıcal significance was assessed as above and the half-life of fluorescence intensity calculated. For the purposes of this study, the lifespan of the labeled pool was determined to be that time point following labeling at which no labeled cells could be detected.

\section{Results}

Long-term detection of PKH-26-labeled lymphocytes

Initial labeling conditions were establıshed according to protocols developed previously for $\mathrm{PKH}-2$ (20). For red blood cells, a titration of both cells and dye was used to establish optima conditions. Following labelıng, both cell types fluoresced at intensities >100-fold above background and exhibited even staıning as assessed by fluorescence microscopy. Labeled lymphocytes routinely remained detectable for 2 months by flow cytometry (Fig. 1). Labeled erythrocytes were equally detectable (not shown). Over the examination period, the intensity of staining of the labeled lymphocytes became more diffuse. This was not seen with labeled erythrocytes, however. After the injection of labeled cells, there was an equilibration period as has been previously described using other labels (27-29). This was reflected in the acute decrease in concentration of labeled lymphocytes and erythrocytes in the blood, as well as the concurrent increase in the concentration of labeled lymphocytes in lymph draining s.c. and intestinal tissues. It was found that the concentration of labeled lymphocytes and erythrocytes in the peripheral blood fluctuated for a period of - 5 days before stabilizing and for this reason only samples taken $>150 \mathrm{~h}$ following injection were included in later experiments

\section{Rate of loss of PKH-26 label from lymphocytes in vivo}

Labeled lymphocytes were identifiable in blood and lymph for $>2$ months, and continued to be easily differentiated from unstained cells. Fluorescence plots from efferent s.c. lymph collections from a representative animal are shown in Fig. 1. There was no detectable transfer of $\mathrm{PKH}-26$ to unlabeled cells in that granulocytes or monocytes were never found to be labeled. Representative regressıon curves from one animal used to determine the rate of dye loss from lymphocytes recovered from intestınal lymph, prescapular lymph and peripheral blood are shown in Fig. 2(a). Data was analyzed from 5 days after injection of labeled cells, as described above. The analysis was based on the rate at which the intensity of the dye on the labeled cells decreased. From the regression equations, a half-life for the loss of fluorescence intensity on s.c. and intestinal lymph cells was calculated (Table 1). Only statistically significant curves were used for later numerical analysis. Although it was always possible to calculate the regression equations for cells recovered from peripheral blood, the trend was not statistically significant, and therefore no numerical calculations for half-life were carried out on these samples

\section{Disappearance of PKH-26-labeled lymphocytes from blood} and lymph

Representative regression curves for the disappearance of labeled recirculating lymphocytes from s.c. efferent lymph, intestinal efferent lymph and peripheral blood from one animal are shown in Fig. 2(b). Data from all three tissues produced significant regression curves, which could be used for numerical analysis. By solving these equations it was possible 


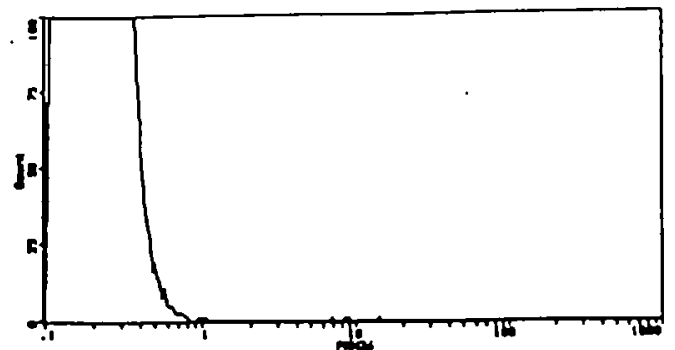

Unstained

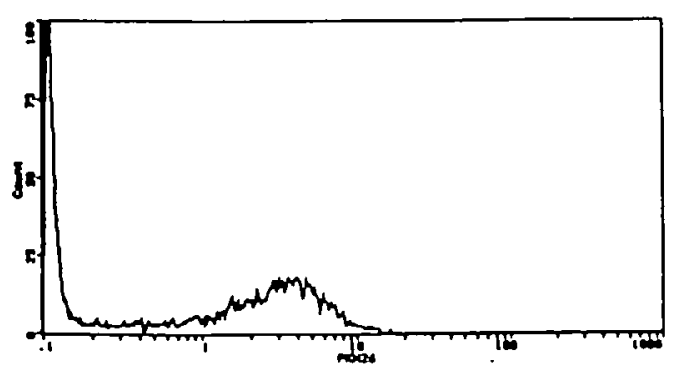

9.1 days

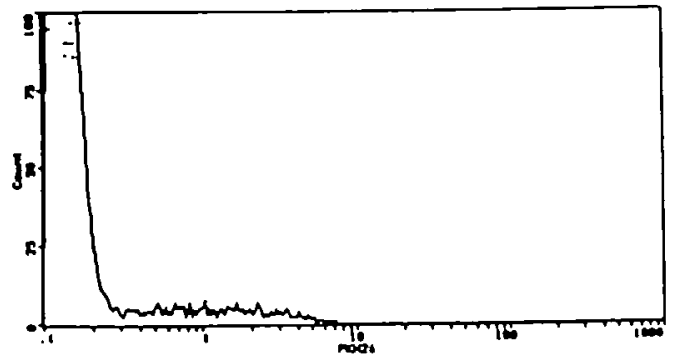

29.9 days

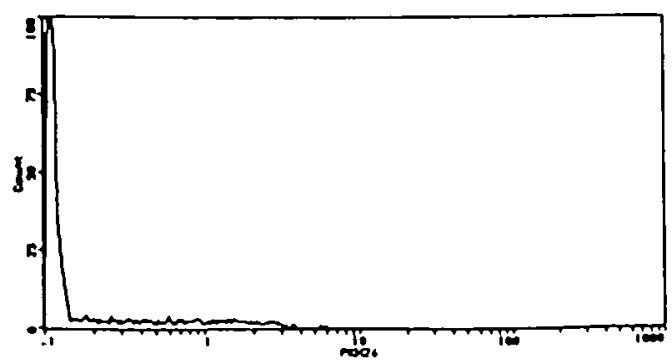

55.3 days

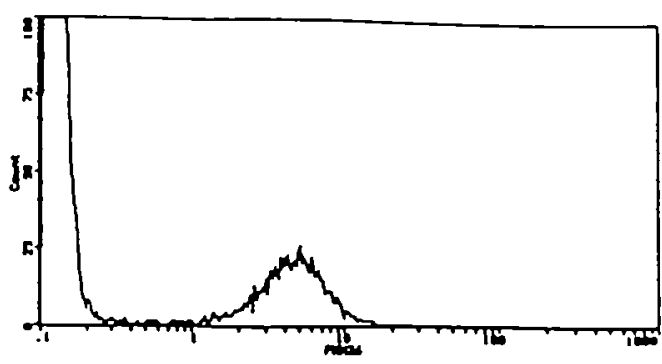

4.9 days

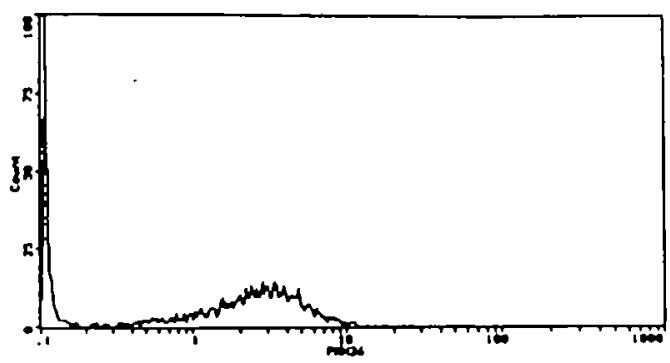

11.4 days

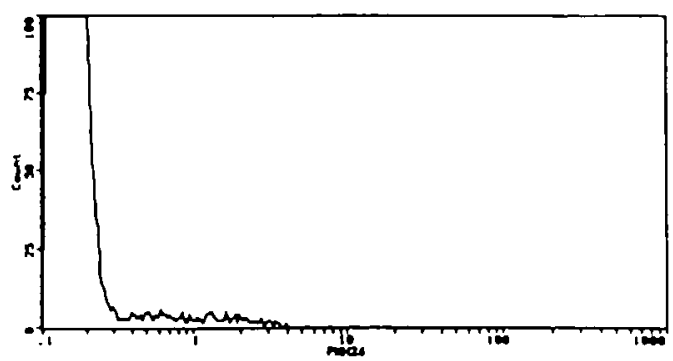

37.8 days

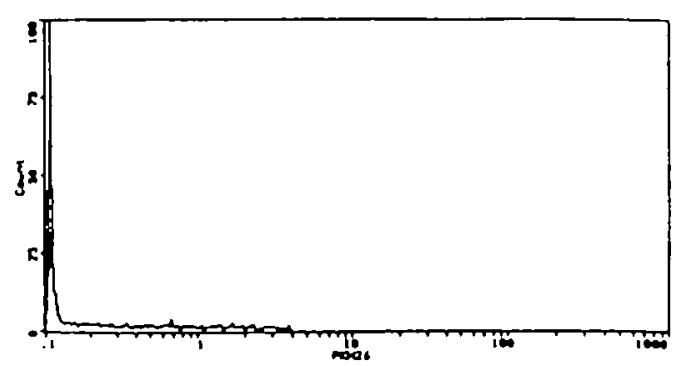

60.9 days

Fig. 1. Histograms depicting representative plots of fluorescence intensity of cells recovered in efferent s.c. Iymph following injection of labeled cells. At the end of the experıment, all samples were analyzed on a Coulter Epics Elite flow cytometer, gated appropriately on $90^{\circ}$ versus forward angle light scatter to include only small lymphocytes. Data is presented as cell number versus $\log _{10}$ fluorescence.

to calculate the time taken to reduce the concentration of labeled cells recovered from each tissue to half its original value. Labeled lymphocytes disappeared from both blood and lymph in an exponential manner, with a calculable half- life. This allowed assessment of the turnover rate, or that time required to replace half the labeled lymphocytes in each compartment through cell death, peripheral cell division or input of new cells from primary lymphoid organs. Pooled 

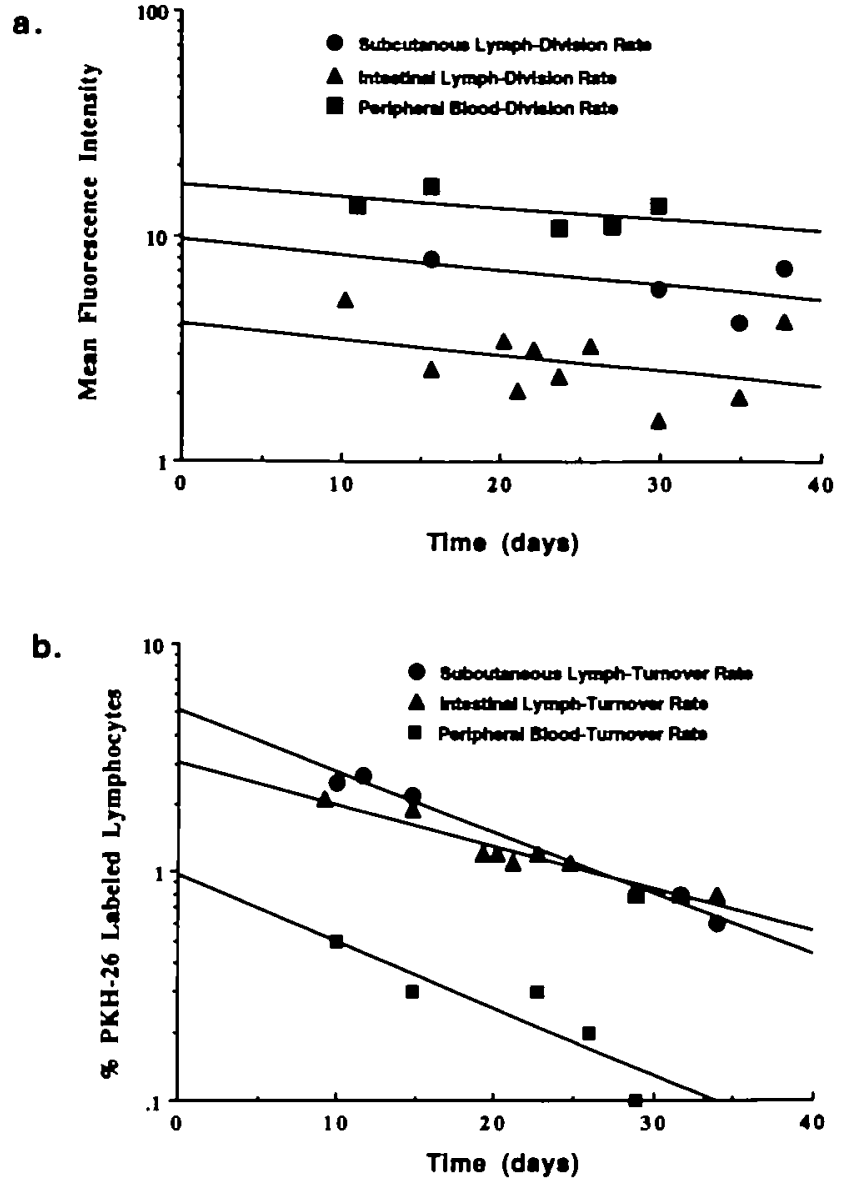

Fig. 2. Plots of fluorescence intensity and recovery of labeled lymphocytes following re-injection Representative plots from one animal depicting the results of data obtained as in Fig 1 (a) Plot depicting the drop in intensity of fluorescence of labeled cells in blood, efferent S C lymph and efferent intestinal lymph following injection. The cells were found to lose fluorescence in an exponential manner, consistent with a constant time for the cell to lose half its label, indicative of cell division. Regression curves were calculated in order to obtain a slope of the line, which could be used to calculate half-life. (b) Disappearance of labeled tymphocytes from blood, efferent s c lymph and efferent intestınal lymph following injection. The disappearance of labeled lymphocytes from all tissues was found to follow an exponential pattern of decay. This allowed prediction of a half-life for lymphocytes or the mean turnover rate

results are shown in Table 1 The calculated rate of turnover in each tissue compartment is shown.

\section{Recovery of $\mathrm{PKH}-26$ labeled erythrocytes in vivo}

Labeled erythrocytes could be detected at measurable levels (up to $0.5 \%$ ) for up to 2 months. At this point, the experiment was terminated. There was no detectable loss of intensity of label over this period. A representative curve is shown in Fig. 3(a). In addition, there was no detectable transfer of label onto other cell types. However, there was a linear rate of disappearance of the labeled cells during this period. When plotted against time (Fig. 3b), a lifespan for red blood cells
Table 1. Rate of loss of fluorescence and turnover of recirculating lymphocytes in vivo

\begin{tabular}{lll}
\hline Tissue & $\begin{array}{l}\text { Label loss rate } \\
\text { (days } \pm \text { SEM) }\end{array}$ & $\begin{array}{l}\text { Turnover rate } \\
\text { (days } \pm \text { SEM) }\end{array}$ \\
\hline Subcutaneous lymph $(n=5)$ & $29.2 \pm 11.4$ & $21.7 \pm 5.3$ \\
Intestinal lymph $(n=3)$ & $305 \pm 7.7$ & $117 \pm 29$ \\
Blood $(n=3)$ & NA & $12.7 \pm 4.2$ \\
Combined & $298 \pm 6.8$ & $16.5 \pm 3.0$ \\
\hline
\end{tabular}

Calculated rates of label loss and turnover of recirculating lymphocytes in each compartment and overall derived from logarithmic regression analysis. The slopes of all curves used in calculation are statistically significant $(P<0.05)$.

NA indicates the lack of statistically significant regression curves for numerical analysis. 'Combined' values represent weighted means

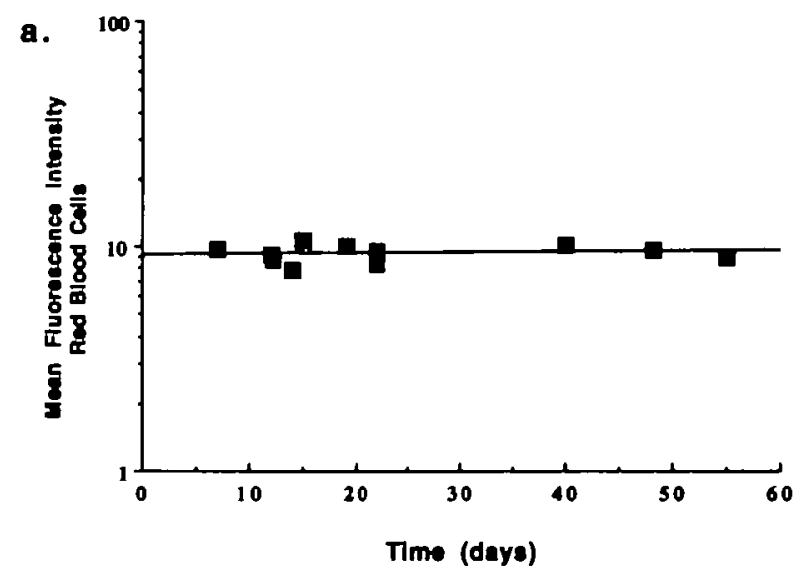

b.

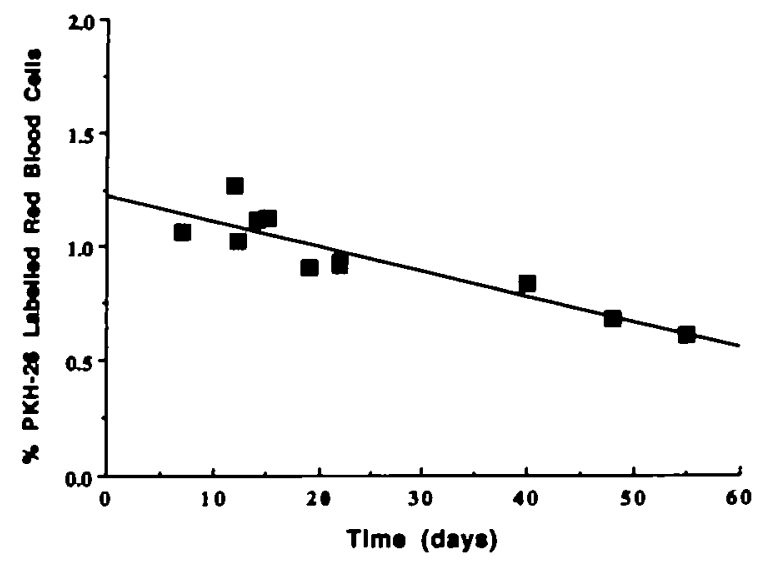

Fig. 3. Plots of fluorescence intensity and recovery of labeled erythrocytes following re-injection. (a) Fluorescence intensity of labeled red blood cells following i.v. injection. No detectable loss of intensity was found, indicating the lack of cell divsion and dye reutilization. (b) Concentration of labeled red blood cells following injection. Red blood cell lifespan was calculated from the linear curve by determining the tıme at which no labeled cells would be present (not shown). Data from one animal is shown. 
could be calculated. The average lifespan of a sheep erythrocyte in vivo was determined to be 153.0 days $(n=2)$.

\section{Discussion}

This is the first report of direct measurement of lymphocyte turnover in vivo. These experiments demonstrate that it is feasible to use the PKH family of lipophilic dyes to track erythrocytes and lymphocytes in vivo for periods of several months, and that it is possible to establish values for the turnover of lymphocyte pools based on direct measurement techniques.

The use of $\mathrm{PKH}-2$ for long-term tracking has been previously established in our laboratory (20). However, the use of PKH-26 for similar experiments has not been demonstrated. Previous studies have demonstrated that the $\mathrm{PKH}$ dye is a valuable tool for cell tracking experiments, with no detectable effect on cell function $(30,31)$. This label has been used previously to establish the nature of short-term lymphocyte migration patterns through the liver (30) In these experiments, no detectable alteration was observed in the short-term mıgratory characteristics of labeled lymphocytes. Cells damaged during labeling, as is observed with other tracking dyes, do not recirculate (32). However, appropriately labeled cells will remain easıly distinguishable and recirculate for long periods of time. Even with a relatively small population of cells labeled, the technique of flow cytometry allows one to easily distinguish the labeled pool from the unlabeled pool.

Previous studies have used radiolabels to establish the lifespan of red blood cells in experimental animals $(16,17)$. Although effective, this method lacks some of the technical advantages of a fluorescence-based protocol. In addition, although there has been some demonstration of the effect of radiolabels on cell function, there has been no demonstrable loss of function of cells following labeling with the PKH labels $(33,31)$. Although studies using chromium and iron have demonstrated 'leeching' of the radiolabel from labeled cells, there was no significant loss of fluorescence from the $\mathrm{PKH}$ labeled erythrocytes over a period of 2 months (17). This indicates that the label is not lost from living membranes in vivo. Data on nucleated cells are still lacking. Our inability to detect other leukocytes that are weakly labeled indicates that there is no re-utilization of the label lost from dying cells.

Red blood cells do not demonstrate any progressive loss of fluorescence over the period observed. When subjected to both linear and exponential regression analysis, the erythrocytes were found to disappear in a linear manner. This indicates a simple age-determined lifespan for sheep red blood cells. Had there been random destruction of the labeled red blood cells, consistent with labeling-induced damage, a rapid exponential decay curve would have been expected (18). Previous data have suggested that there may be multiple populations of red blood cells which can be differentiated by their lifespans in vivo (34). Our data do not support this. Simple analysis of the slope of the regression line led to calculation of a mean lifespan for sheep erythrocytes of 153 days.

Previous methods to determine lymphocyte lifespan have included incorporation of DNA precursors, arrest of cell proliferation, adoptive transfer experiments and persıstence of altered karyotypes (13). In vivo lifespan of lymphocytes based on incorporation of DNA precursors provides indirect data based on appearance rates of labeled cells and persistence of unlabeled cells in the periphery. Difficulties may result due to unequal labeling of peripheral tissues and possible toxicıty of the utilized precursor (14). Because exogenous nucleotides are utllized in the salvage pathway, they may fail to label mature lymphocytes in the periphery which may use the de novo pathway of DNA synthesis (35). It has been suggested, therefore, that this method only demonstrates a minimal estimate of cell division in vivo (13). Methods relying on persistence after cell transfer and persistence after arrest of cell production also provide interpolative data In addition, such a perturbation of the immune system may cause normal homeostatic mechanisms to alter the normal lifespan of lymphocytes (13). The relative contributions of peripheral cell division and input from primary lymphoid tissue cannot be distinguished. Finally, analysis based on persistence of lymphocytes with altered karyotypes following non-lethal irradiation may also affect the lifespan of the pool observed (15). Evidence suggests that the degree of radiation damage may affect the overall lifespan of the measured lymphocyte. Karyotype-based techniques do, however, allow rare cell analysis.

PKH-based protocols to assess pool turnover are not subject to these difficulties Previous data have demonstrated in vitro that rates of cell division of $\mathrm{PKH}$-labeled cells can be calculated based on successive halving of intensity of the $\mathrm{PKH}$ label following cell divisıon (19). This provides a more direct method to assess the rate of cell division than the incorporation of labeled DNA precursors. In addition, this protocol involves an ex vivo labeling procedure, allowing more stringent control over labeling efficiency than with bromodeoxyuridine labeling (14). Unfortunately, in vivo results are not as easily interpretable as in vitro data. In vitro experıments with synchronized cells clearly demonstrated discrete drops in the intensity of label during cell division, rather than a gradual shift as is seen in the in vivo situation (19). Although leeching of label from cells has not been observed in vitro or in vivo, there is a gradual loss of intensity from lymphocytes. Although some dye loss must be indicative of cell division, in vivo dye loss may also correlate with cell metabolism. It was observed that there was a gradual redistribution of the label within the cells over time. This was seen as a shift from a diffuse surface staining to a highly localized internal staining as assessed by fluorescence microscopy (not shown). Previous studies have suggested that there may be some loss to endothelial cells during migration; however, it was not possible to detect significant levels on endothelial cells in our studies (31). No other cell types were found to acquire label over the course of the experiment. The rate at which the dye intensity halved on lymphocytes was found to follow an exponential function. This is in agreement with a hypothesis describing the gradual halving of dye intensity at a constant rate, relative to metabolic function and cell division. Calculation of the mean rate of loss in intestinal and s.c. lymph demonstrated no significant differences. The mean division rate was found to be -30 days. Although it was not possible to definitively calculate the lifespan of lymphocytes based on the loss of label over time, this 30 day 
dye loss rate must be at least a maximal estimate of peripheral lymphocyte division withın the recirculating pool

The rate at which the labeled cells disappeared in the lymph compartments appeared to follow an exponential function as well. As there does not appear to be evidence for significant dye loss in vivo, this indicates a definable rate of turnover of lymphocytes. This value must be a function of the rate at which cells leave the compartment through death and the rate at which newly formed cells enter the compartment. Regression analysis allowed calculation of this rate through analysis of the speed at which labeled cells disappeared from the blood and lymphatic circulations. Calculation of the half-life for these mathematical functions demonstrated a mean turnover rate of efferent s.c. lymph of $\sim 22$ days. In contrast, efferent intestinal lymph appeared to turn over every 12 days and the blood lymphocytes repopulated every 13 days. Due primarily to intra-anımal variation, there is no significant difference between these values. The overall mean time for the turnover of the recirculating pool is 16.5 days.

The experiments described here were undertaken in order to further understand the steady-state nature of recirculating lymphocyte pools in vivo. Prior to this work, little was known

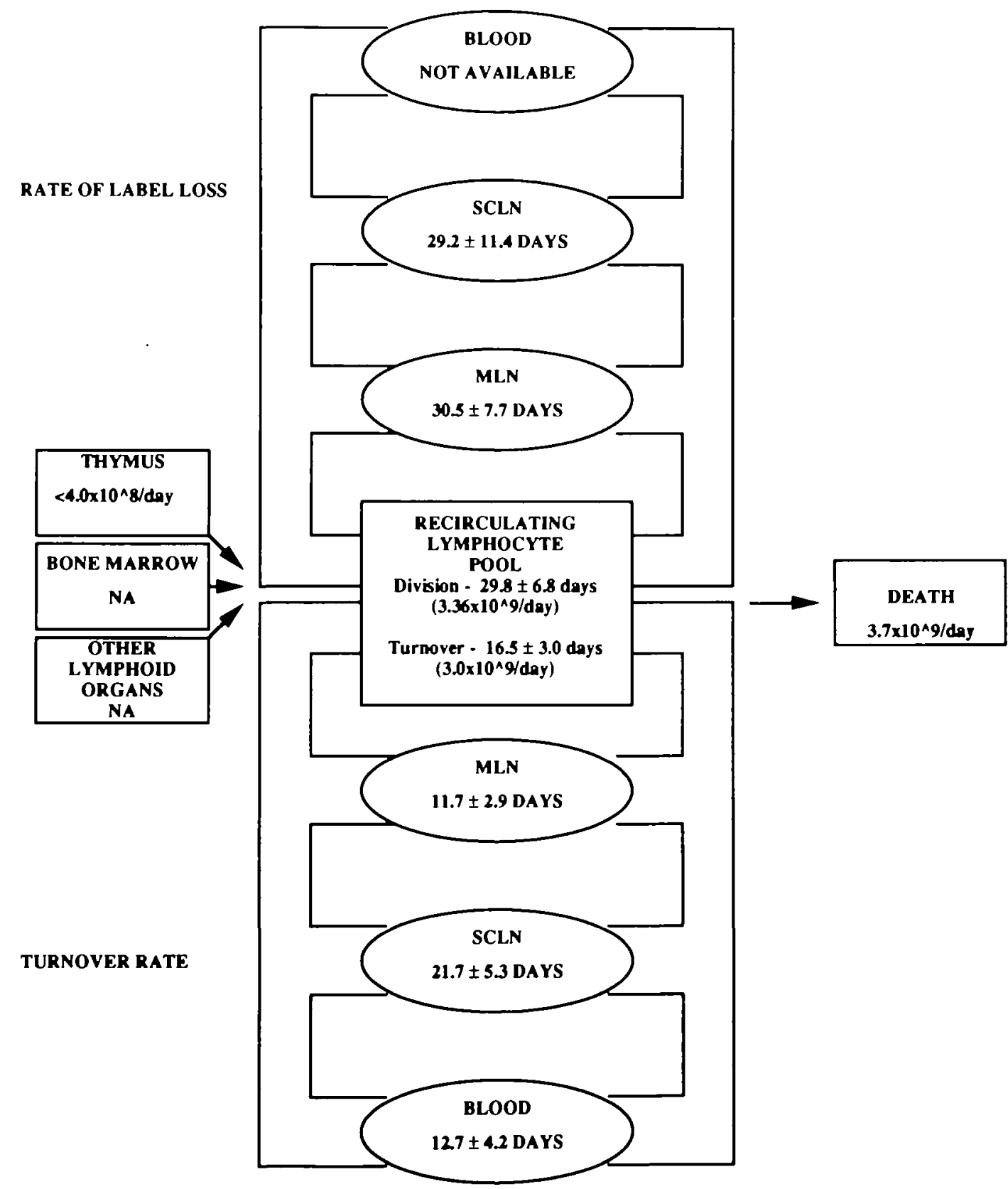

Fig. 4. Schematic representation of the lifespan and turnover of recirculating lymphocytes in vivo (NA, data not available) 
regarding the nature of recirculating lymphocytes except absolute numbers of cells. No such direct measurement of pool turnover rates and cell lifespans has been available. Tissue specificity does not appear to play a major role in the rate at which the pool replicates through cell division or input from primary lymphoid organs. It was found that the loss of label from lymphocytes in both mesenteric and s c. efferent lymph was similar. This may indicate similar metabolic rates within these two compartments or maximal rates of cell division associated with normal immune stimulation occurring in outbred animals. Using this value, it is possible to calculate a balance sheet for pool turnover and cell division withın the recirculating lymphocyte pool. The following calculations are schematized in Fig. 4. Estimating the recirculating pool at $1 \times 10^{11}$ lymphocytes and assuming a random probability of cell division, $1 \times 10^{11}$ lymphocytes divide every 29.8 days (Table 1). This would suggest that $1 \times 10^{11} / 29.8$ or $336 \times 10^{9}$ lymphocytes divide each day, presumably within the peripheral lymphoid organs. It has been estimated that the thymic input from a 3-month-old lamb is $4.0 \times 10^{8}$ lymphocytes per day (36). Export rates from the thymus in more mature animals are likely to be somewhat lower. Input rates of lymphocytes from bone marrow and Peyer's patches for 6- to 12-monthold lambs are as yet unknown. The contribution to the recirculating pool from the formation of new cells in secondary lymphoid organs is unclear. Data from Hall and Morris (37) suggests that under normal circumstances, cell division within the lymph node contributes $<1-2 \%$ of the small lymphocytes in efferent lymph. During an immune response, this number can increase. Although there is also considerable cell division within other lymphoid organs, the contribution that this makes to the recirculating lymphocyte pool has not been assessed Adding the input from primary lymphoid organs to the calculated division rate above provides a total new cell input of $\sim 3.76 \times 10^{9}$ lymphocytes per day. In order to maintain a constant pool size, an equal number must be removed through cell death. Experimentally, we found that the recirculating pool turns over on average every 16.5 days (Table 1). Experimentally, $50 \%$ of the labeled pool is replaced every 16.5 days. This would suggest that $5 \times 10^{10}$ lymphocytes die each 16.5 days or $3.03 \times 10^{9}$ lymphocytes die each day. Overall, this value is close to the predicted value of $3.76 \times 10^{9} \mathrm{cells} /$ day.

This suggests that long-term PKH labeling may be an effective way to measure the lifespan of lymphocytes in vivo. Such data is of primary interest to understanding the nature of the in vivo immune response. This report represents the first demonstration of direct measurement of lymphocyte turnover. and lifespan in vivo. Phenotypic analysis of labeled lymphocytes can now explore directly the lifespan of memory and naive lymphocytes in vivo. Further studies can now be directed to directly establish the turnover of other cell types in vivo. The turnover and lifespan of lymphocytes and of other leukocytes is fundamental to the overall immune or disease status of an individual, and future direct measurements in animals and man are now feasible.

\section{Acknowledgements}

The authors with to gratefully acknowledge Heather Begley for analysis of cell samples on a Coulter Elite flow cytometer and the continued support of Zynaxis Cell Science, Malvern PA. This work supported by MRC Canada. A. $Y$ is the recipient of a MRC Canada Studentship

\section{References}

1 Sprent, J. and Tough, D. F. 1994. Lymphocyte life-span and memory Science 265:1395.

2 Gray, D. and Skarvall, H. 1988. B cell memory is short-Irved in the absence of antigen. Nature 336:70.

3 Gray, D and Matzinger, P. 1991 T cell memory is short-lived in the absence of antigen. $J$ Exp Med. 174:969.

4 Smith, J. B., Cunningham, A. J., Lafferty, K. J. and Morris, B. 1970. The role of the tymphatic system and lymphoid cells in the establishment of immunologıcal memory. Aust J. Exp. Biol. Med Sci 48.57

5 Springer, T A. 1994 Traffic signals for lymphocyte recirculation and leukocyte emıgration the multistep paradigm. Cell 71:301.

6 Picker, L J 1994. Control of lymphocyte homing. Curr. Opin Immunol. 6.394.

7 Hall, J. G and Morris, B. 1963. The lymph-borne cells of the immune response. Q. J. Exp. Physiol. 48:235.

8 Young, A J., Hay, J. B. and Mackay, C. R. 1993. Lymphocyte migration in vivo. Curr. Top. Microbiol. Immunol. 184:161

9 Abernethy, N J and Hay, J B 1992 The recirculation of lymphocytes from blood to lymph: physiological considerations and molecular mechanisms Lymphology 25.1.

10 Heın, W. R. 1995. Sheep as experimental anımals for immunological research. The Immunologist 3.12

11 Michie, C A, Mclean, A., Alcock, C and Beverley, P C. C. 1992. Lifespan of human lymphocyte subsets defined by CD 45 isoforms Nature 360.264.

12 Mackay, C. R, Marston, W L. and Dudler, L 1990. Naive and memory $T$ cells show distinct pathways of lymphocyte recirculation. J Exp. Mod 171.801

13 Freitas, A. A. and Rocha, B. B. 1993. Lymphocyte lifespans. homeostasis, selection and competition Immunol Today 1425.

14 Rocha, B., Penit, C., Baron, C., Vasseur, F., Dautigmy, N. and Freltas, A. A. 1990 Accumulation of bromodeoxyuridine-labelled cells in central and peripheral lymphoid organs: minimal estimates of production and turnover rates of mature lymphocytes. Eur J. Immunol. 20.1697.

15 Decat, G. and Leonard, A. 1980 Lymphocyte lifetime in the rabbit measured by the decline in radiation-induced chromosome damage. Int. J. Radiat Biol 38:179.

16 Eadie, G. S., Smith, W. W. and Brown, I. W., Jr 1960. The use of DFP32 as a red cell tag with and without simultaneous tagging with chromium-51 in certain animals in the presence or absence of random destruction. J. Gen. Physiol. 43:825.

17 Giles, R. C., Jr, Berman, A, Hildebrandt, P. K and McCaffrey, R. P. 1975. The use of Cr51 for sheep red blood cell survival studies. Proc. Soc Exp Biol Med 148.795.

18 Eadie, G. S. and Brown, I. W., Jr 1953. Red blood cell survival studies. Blood 8.1110 .

19 Horan, P. K. and Slezak, S. E. 1989. Stable cell membrane labelling. Nature 340.167.

20 Teare, G. F., Horan, P K, Slezak, S. E., Smith, C. and Hay, J. B. 1991. Long term tracking of lymphocytes in vivo the migration of PKH-labelled tymphocytes. Cell. Immunol. 134:157.

21 Jensen, B. D., Schmitt, T. C. and Slezak, S E. 1990. Labelling of mammalian cells for in vivo cell tracking by a fluorescence method. Progr. Clin. Biot. Res. 355:199.

22 Schnappauf, H. and Schnappaut, U. 1968 Drainage of the thoracic duct and amount of the 'easily mobilized' tymphocytes in calves, sheep and dogs. Blut 16:209.

23 Glover, D. J. and Hall, J. G. 1976. A method for the collection of lymph from the prescapular lymph node of unanaesthetized sheep. Lab. Animals 10:403.

24 Hall, J. G 1967. A method for collecting lymph from the prefemoral lymph node of unanaesthetized sheep. Q. J. Exp. Phys. Cog Med Sci. 52:403. 
25 Lascelles, A K. and Morris, B. 1961. Surgical techniques for the collection of lymph from unanaesthetized sheep. $Q$. J Exp. Physiol. 46.199.

26 Glantz, S A. 1987. Primer of Biostatistıcs, 2nd edn, p. 191. McGraw-Hill, New York

27 Cahill, R N. P. Poskitt, D. C., Frost, H. and Trnka, Z. 1977 Two distinct pools of recirculating $T$ lymphocytes: migratory characteristics of nodal and intestinal T lymphocytes. J. Exp. Med. $145 \cdot 420$.

28 Chin, G. W and Hay, J. B 1980 A comparison of lymphocyte migration through intestinal lymph nodes, subcutaneous lymph nodes, and chronic inflammatory sites of sheep Gastroenterology 791231.

29 Issekutz, T, Chin, W. and Hay, J B. 1980. Lymphocyte traffic through granulornas differences in the recovery of indium-111 labelled lymphocytes in afferent and efferent lymph. Cell Immunol 54:79.

30 Young, A J, Hare, G. M. T. and Hay, J. B. 1994. Blood to lymph migration of small lymphocytes through the liver of the sheep. Hepatology 19:758
31 Samlowski, W. E., Robertson, B A., Draper, B K., Prystas, E. and McGregor, J R 1991. Effects of supravital fluorochromes used to analyze the in vivo homing of murine lymphocytes on cellular function. $J$ Immunol. Methods 144.101.

32 Heslop, B. F and Hardy, B. E. 1971. The distribution of 51-Crlabelled syngeneic and allogeneic lymph node cells in the rat Transplantation 11:128.

33 Frost, H., Frost, P., Wilcox, C. and Thrall, J. 1979. Lymph node scanning in sheep with indium-111-labelled hymphocytes int. J. Nucl. Med Biol 6.60.

34 Blunt, M. H., ed. 1975. The Blood of Sheep: Composition and Function, p. 38 Springer Verlag. New York.

35 Reichard, P. 1988. Interactions between deoxyribonucleotide and DNA synthesis Annu Rev Brochem 57. 349.

36 Witherden, D. A., Kimpton, W. G., Abernethy, N. J. and Cahill, R N. 1994. Changes in thymic export of gamma delta and alpha beta $T$ cells during fetal and postnatal development Eur. $J$. Immunol. 24:2329

37 Hall, J. G. and Morris, B. 1965. The origin of the cells in the efferent lymph from a single lymph node. J. Exp. Med 121:901. 
